\title{
REPRODUCTIVE BIOLOGY OF THE GASTROPOD STROMBUS LUHUANUS (STROMBIDAE)
}

\section{$\operatorname{AUTHOR}(\mathrm{S})$ :}

Kuwamura, Tetsuo; Fukao, Ryuzo; Nishida, Mutsumi; Wada, Keiji; Yanagisawa, Yasunobu

\section{CITATION:}

Kuwamura, Tetsuo ...[et al]. REPRODUCTIVE BIOLOGY OF THE GASTROPOD STROMBUS LUHUANUS (STROMBIDAE). PUBLICATIONS OF THE SETO MARINE BIOLOGICAL LABORATORY 1983, 28(5-6): 433-443

\section{ISSUE DATE:}

1983-12-26

URL:

http://hdl.handle.net/2433/176065

RIGHT: 


\title{
REPRODUGTIVE BIOLOGY OF THE GASTROPOD STROMBUS LUHUANUS (STROMBIDAE) ${ }^{1)}$
}

\author{
TETSUO KUWAMURA \\ Faculty of Liberal Arts, Chukyo University, Yagoto Honmach, Nagoya, 466 Japan \\ Ryuzo FUKAO \\ Institute of Environmental Toxicology, Uchimoriya, Mitsukaido, 302-02 Japan \\ Mutsumi NISHIDA \\ Department of Marine Sciences, University of the Ryukyus, Nishihara, \\ Okinawa, 903-01 Japan \\ KEIJI WADA \\ Seto Marine Biological Laboratory, Kyoto University \\ and \\ YASUNOBU YANAGISAWA \\ Department of Biology, Ehime University, Bunkyo, Matsuyama, 790 Japan
}

With Text-figures 1-9 and Tables 1-2

\begin{abstract}
Strombus luhuanus breeds in the summer from June to August at Snirahama. To copulate, the male follows the trail of the female or approaches the stationary female mounted on by another male. The female lays an egg mass either alone or being mounted by the male(s). Copulation and spawning occur mainly at the sand-pebble areas both in the shallow waters, where the conch appears only in the breeding season, and in the deep $(<20 \mathrm{~m})$ waters. Factors affecting upon selection of spawning sites are discussed.
\end{abstract}

\section{Introduction}

The genus Strombus is a tropicopolitan mesogastropod belonging to the family Strombidae (Abbott, 1960). Reproductive biology has been most intensively studied in Strombus gigas (Robertson, 1959; Randall, 1964; D'Asaro, 1965; Brownell, 1977). Copulation behavior and egg laying process of $S$. costatus are described in detail by Berg (1975): In some other species, information on eggs and/or spawning site and season are available (Risbec, 1936; Ostergaard, 1950; Robertson, 1959; Abbott,

1) Contributions from the Seto Marine Biological Laboratory, No. 695.

Publ. Seto Mar. Biol. Lab., XXVIII (5/6), 433-443, 1983.

(Article 8) 
1960; D'Asaro, 1970; Brownell, 1977). There is, however, no information in literature on the reproductive biology of the Pacific species Strombus luhuanus (Linnaeus).

During the course of our study on the ecology of S. luhuanus at Shirahama on the Pacific coast of Japan, we carried out observations on its reproductive biology. The present paper describes the sexual dimorphism, mating and spawning behavior, structure of the egg mass, and breeding site and season of $S$. luhuanus.

\section{Material and Methods}

Submarine observations were carried out by using SCUBA or by snorkelling around the Seto Marine Biological Laboratory, Shirahama $\left(33^{\circ} 42^{\prime}, 135^{\circ} 20^{\prime} \mathrm{E}\right.$; Fig. 1), during a period from April 1976 to July 1977. Environmental conditions of the study area are described in detail by Wada et al. (1983). Numbers of pairs mounting (or copulating) and those of egg masses as well as total number of individuals of $S$. luhuanus were counted monthly at the fixed zones, one meter wide, along Lines 1 and 2 (both $700 \mathrm{~m}$ long) and Line $3(50 \mathrm{~m}$ long: St. B). These were also censused at Sts. A, C and D and nearby areas, occasionally.

At each of the shallow station (5 $\mathrm{m}$ deep; $100 \mathrm{~m}$ offshore along Line 1) and the deep station (13 $\mathrm{m}$ deep; $450 \mathrm{~m}$ offshore along Line 1) (Fig. 1), about 40 adults were collected monthly. Shell length, total weight, body weight, gonad weight,

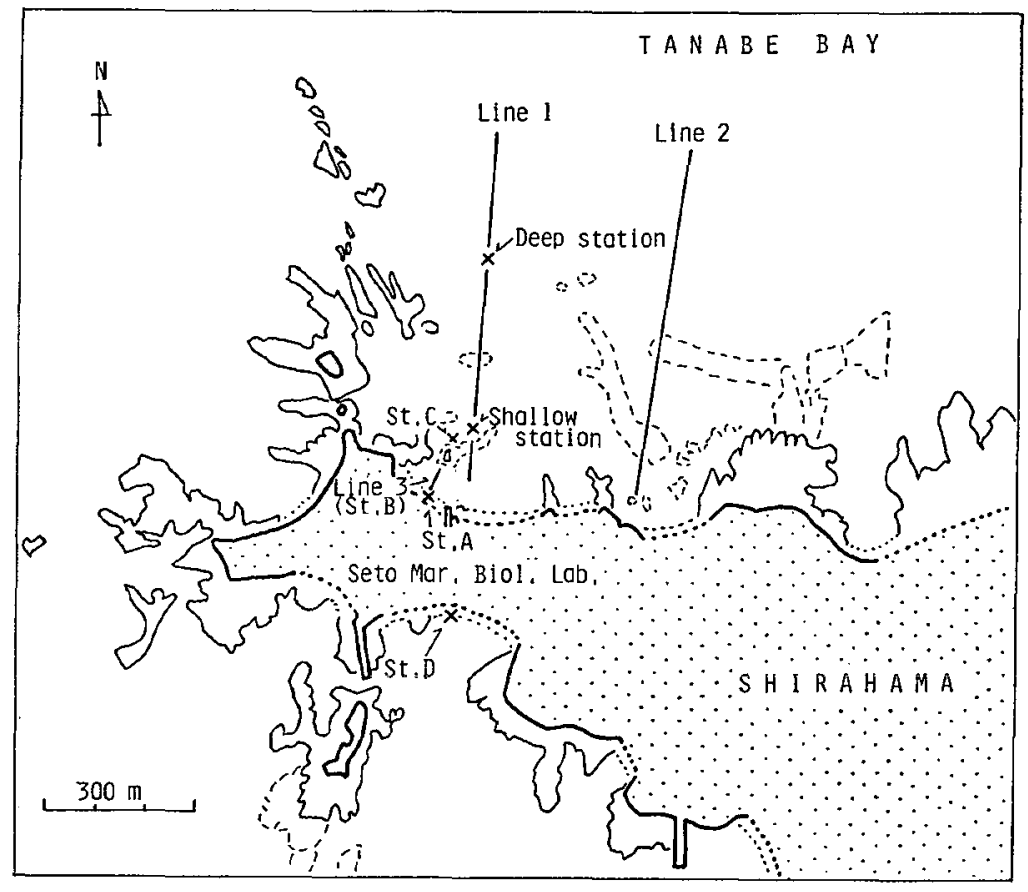

Fig. 1. Map of the study area. Shore lines at the highest and the lowest tides are illustrated by dotted lines (sand or pebble shores) and solid lines (rocky shores). Profiles of submerged rocky reefs are shown by broken lines. 
and length of the penis or clitoris were measured. Several egg masses were collected, and their sizes, numbers of eggs in them, and diameters of eggs were measured.

Fifteen observations on mating behavior, each lasting one or two hours (23 hours in total), were made in the vicinity of St. G (Fig. 1). In each observation, individuals of $S$. luhuanus in an area about $40 \mathrm{~cm}$ square were followed, and their behavior and interactions were recorded. When an animal under observation moved out the original square, the observation square was enlarged to follow its movement. At the end of each observation all the observed individuals were collected, and later measured and sexed in the laboratory.

On June 27, 1976, 410 adults were collected, tagged and released at St. B, and their locations were traced afterwards.

\section{Results}

Sexual Dimorphism. The male of Strombus luhuanus bears an open-grooved spadelike penis, which is brownish black except the pale brown distal blade, on the right dorsal side of the foot (Fig. 2a). The average length of the penis was $9.3 \mathrm{~mm}(\mathrm{n}=$ 370). The female has a genital groove running across the foot into the pedal groove

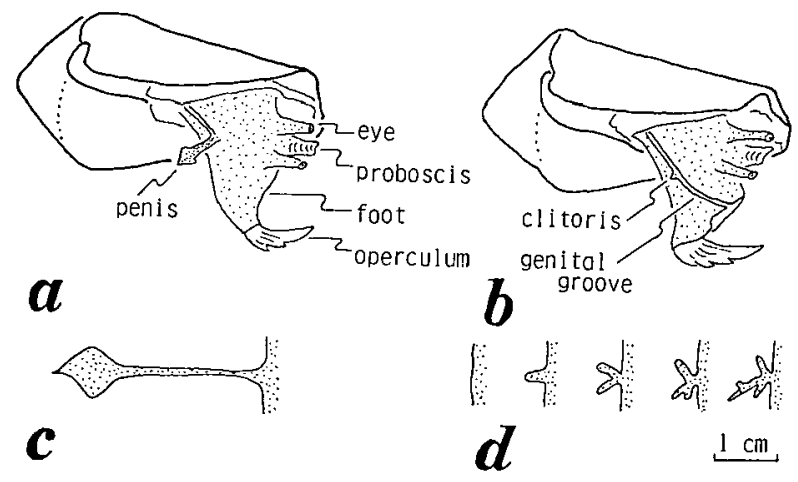

Fig. 2. Sexual dimorphism in Strombus luhuanus. a: male; b: female; c: penis of the male in distended phase; $c$ : variation in the shape of the female's clitoris.

at the base of the anterior end of the foot (Fig. 2b). A small, penis-like, pale brown projection, which was a simple prong or strongly bilobed (Fig. 2d), was found in $71 \%$ of 401 females. The "clitoris" was $3.3 \mathrm{~mm}$ long on the average $(8.8 \mathrm{~mm}$ in the longest).

The average shell length of females was significantly larger than that of males (Fig. $3 ; \mathrm{P}<0.01$, t-test). The ratio of body weight to total weight in females $(\overline{\mathrm{x}}=$ $0.256, n=163)$ was greater than that of males $(\bar{x}=0.246, n=150)(P<0.01, t$-test $)$.

Mating Behavior. Copulation takes place in S. luhuanus. A male catches a female to cling to her shell by his foot, and then places the anterior portion of his shell over her shell lip, locating himself to the posterior-right of and above her; we call this 


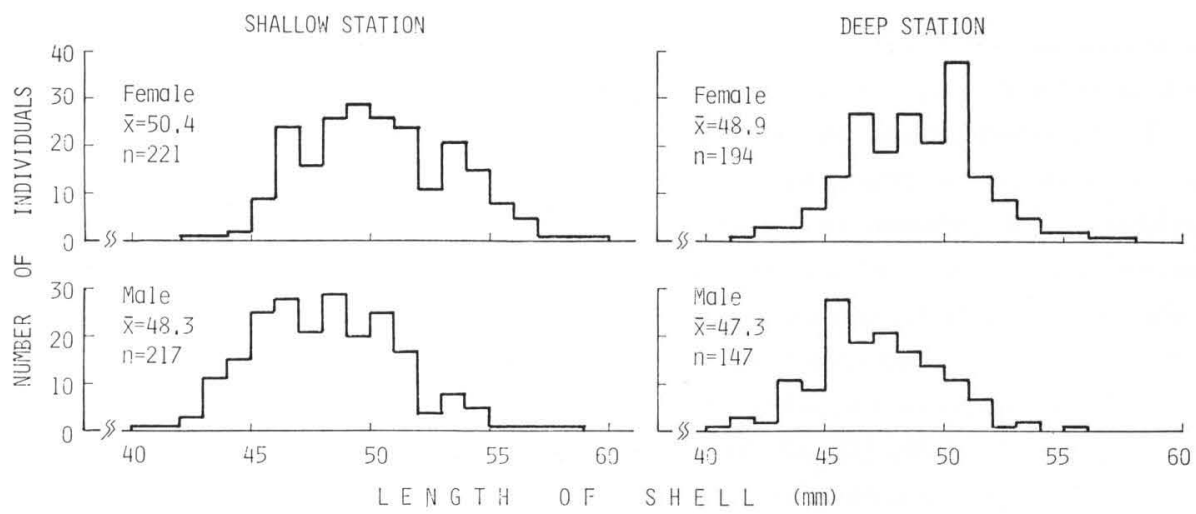

Fig. 3. Size frequency distribution of males and females of $S$. luhuanus collected at the shallow station (left) and the deep station (right).
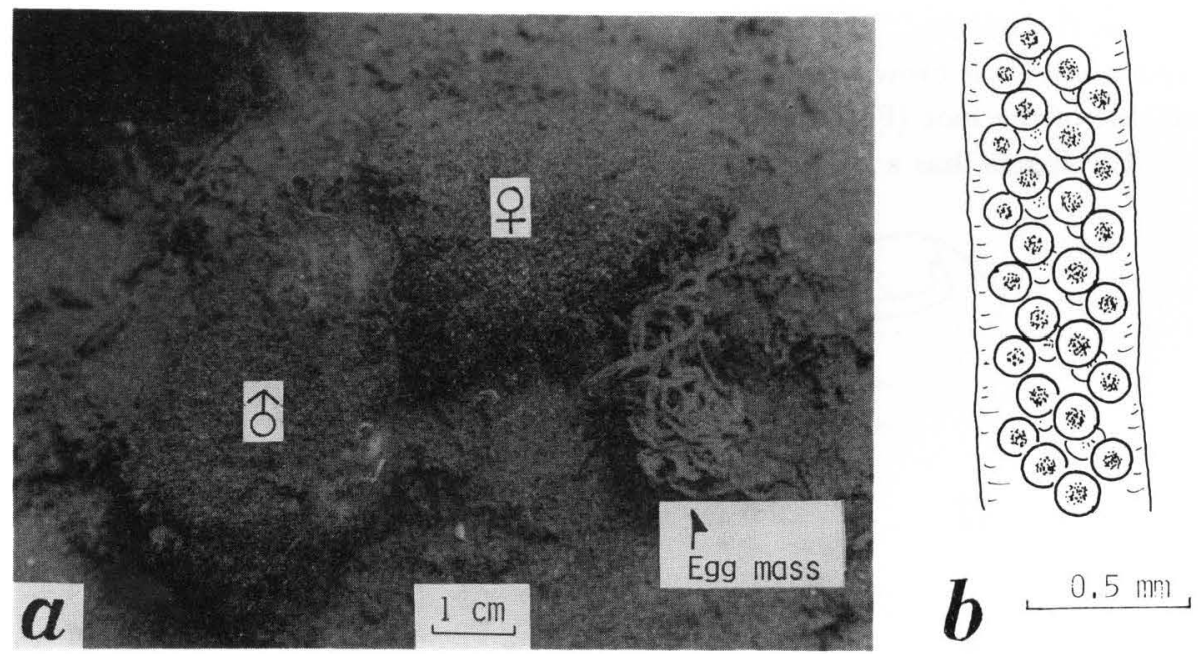

Fig. 4. a: mounting and spawning of $S$. luhuanus, underwater photograph taken at Shirahama by T. Kuwamura; b: a part of the egg tube, sand grains being removed to show egg capsules.

posture "mounting" (Fig. 4a). While mounting, the male inserts his penis through the siphonal notch of the female. When a copulating pair was separated by the observer, the male quickly retracted his spade-like penis (Fig. 2c), which was extended as long as $4 \mathrm{~cm}$. While mounting, the male often grazed on epiphytes on the shell of the female partner, which sometimes grazed on the bottom in her vicinity. Some pairs continued mounting (and probably copulation) throughout the observation period of two hours. Copulation was seen at night as well as in the daytime. Sometimes two to four males were found mounting on a female, but only one, or two in an exceptional case, of the males inserted his penis into the mantle cavity of the female.

To copulate, a male follows the trail of a mobile female or approaches a stationary female. In the former case, a male follows a female keeping a distance less 
than $1 \mathrm{~m}$, and when she stops movement, he approaches her and tries mounting on her. When the female resumes movement, the male follows her again. The repetitive follow-touch behavior lasted more than two hours in a case of observations (Fig. 5). A male also approaches a mounting pair and touches or mounts on the female; then a multi-male aggregation is formed (Fig. 6). When a new-commer

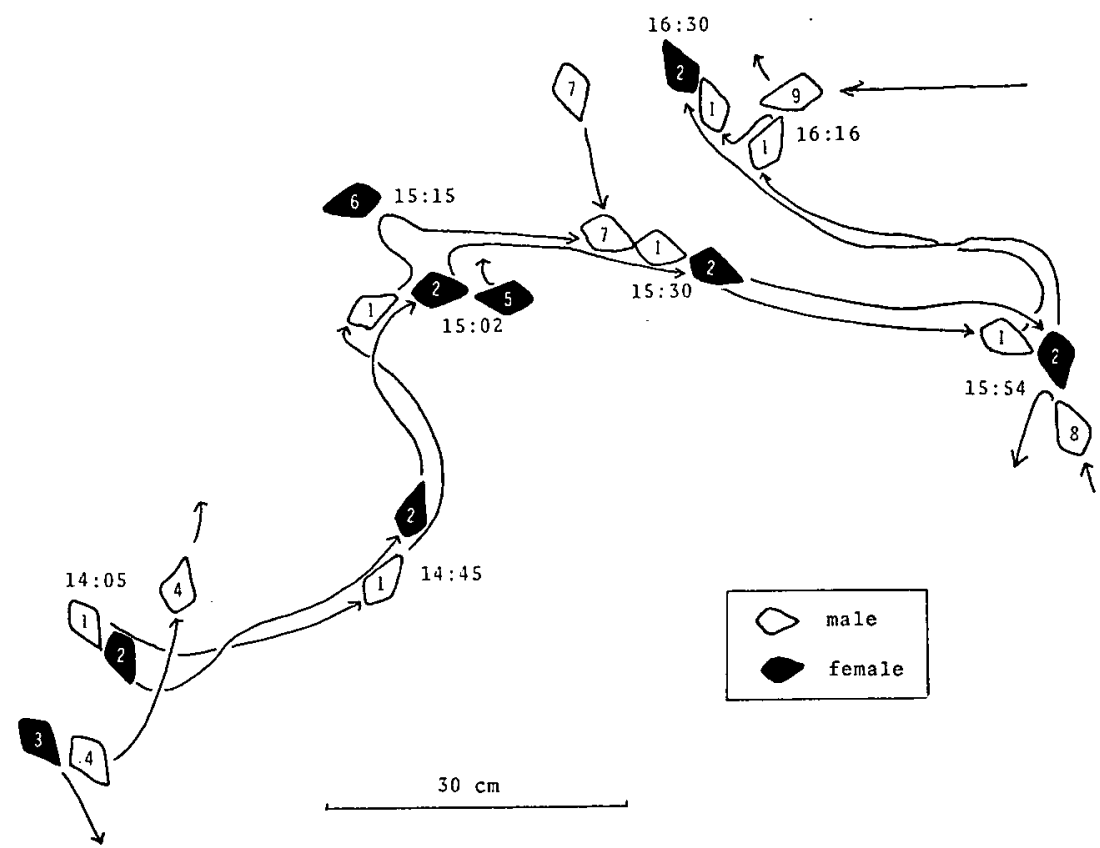

Fig. 5. An example of the repetitive follow-touch behavior; observed on July 30,1976 at the sand floor near rocky reef at depth of $3 \mathrm{~m}$. 14:05 A male (1) is mounting on a female (2), which is feeding. 14:25 2 begins to move, 1 follows 2 . Anothre male (4) comes across 2. 15:02 2 approaches another female (5), and feeds on the surface of the shell of 5. 15:15 1 approaches another female (6). 15:30 A male (7) comes near and follows 1 and 2. 15:54 A male (8) comes into a head-on collision with 2, and then both turn back. 16:16 1 approaches a male (9). 16:30 1 is still following 2 .

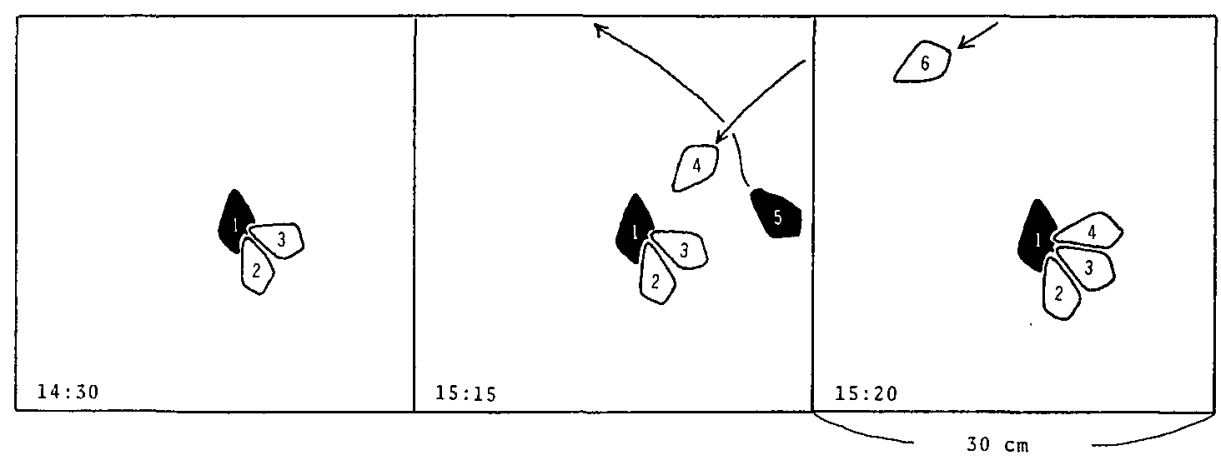

Fig. 6. An example of the formation of a multi-male aggregation; observed on July 30, 1976 at sand-pebble bottom at depth of $5 \mathrm{~m}$. 14:30 Two males (2 and 3) are mounting on a female (1), which is laying eggs. 15:17 Another male (4) approaches the three and mounts on 1. 15:35 Three males (2, 3 and 4) are still mounting on the female (1). 
touched the mounting male, the former was driven away by the latter's agonistic behavior of moving his operculum up and down several times or of waving his proboscis at the former. The new-commer was once observed to respond by waving his proboscis at his opponent; then their proboscises knocked against each other, but finally the new male was driven away. The multi-male aggregation usually broke up, when a female moved away from it. Though there were slightly fewer males than females in adult populations (Fig. 3), multi-male aggregations were often found.

Spawning and egg. The female laid eggs mostly alone, but sometimes did being mounted on by the male(s) (Fig. 4a). In a case of observations, a female, which was mounted on by a male, was moving her propodium up and down, and back and forth, sometimes pushing sand beneath her by the proboscis. These movements may be a part of the process of forming the egg threads into a mass, incorporating sand grains with them. During this process the female buried herself slightly in the sand where the egg mass was laid. It was not clarified how long it took the female to complete spawning.

Egg masses were partially buried in the sand or attached to pebbles or rocks. An egg mass consists of a single continuous tube to which sand grains are adhered. A thread of egg capsules is coiled within a tube, with five or six egg capsules per coil (Fig. 4b). The tube is folded back and forth upon itself, resulting in an oblong compact mass (Fig. 4a). The largest egg mass was about $1 \mathrm{~cm} \times 5 \mathrm{~cm}$. The average width of the egg tube was $0.52 \mathrm{~mm}$, and the average diameter of the egg capsule was $0.13 \mathrm{~mm}$. The length of the egg tube in three complete egg masses was $4.4 \mathrm{~m}$, $7.4 \mathrm{~m}$ and $8.0 \mathrm{~m}$. The number of egg capsules, counted from three different onecentimeter segments of the egg tube, was 255, 280 and 396. Hence, the estimated number of eggs in one egg mass was 112000 to 317000 .

Free-swimming veligers hatched out from an egg mass collected just after being laid, on 6th day in a tank with gentle aeration at about $20^{\circ} \mathrm{C}$.

Breeding Site and Season. Observations in 1976: Copulating animals were found from May 23 to August 29, and egg masses were seen from June 3 to August 4. Both copulation and spawning were seen at various habitats, where the bottom was pebble, sand-pebble, sand, muddy sand (sometimes covered with Zostera), or flat rock thinly covered with sand, in depth of 0.5 to $20 \mathrm{~m}$. Occurrence of mounting adults and

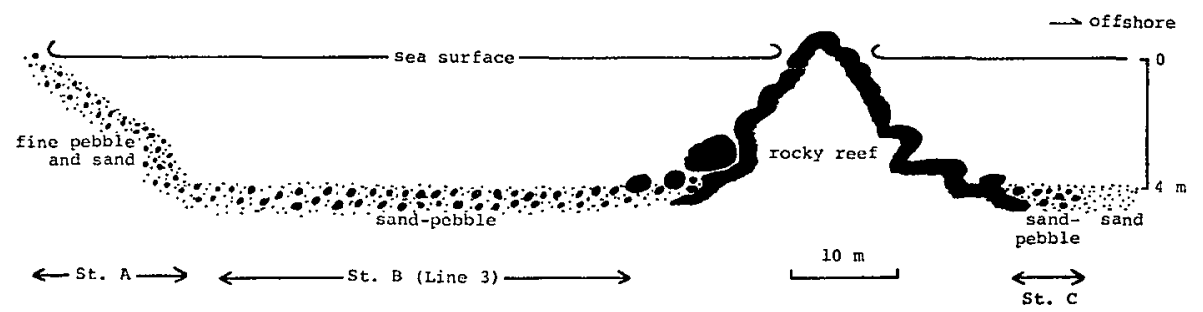

Fig. 7. A schematic representation of the vertical section of the near-shore areas including Sts. A, B and C. 
Table 1. Occurrence of mounting pairs and egg masses in the near-shore areas, Sts. A, B and $C$, in 1976.

\begin{tabular}{rccccccccc}
\hline & \multicolumn{3}{c}{ St. A } & & \multicolumn{3}{c}{ St. B } & \multicolumn{3}{c}{ St. C } \\
& A & M & E & A & M & E & A & M & E \\
\hline May 20 & - & - & - & - & - & - & & no observation \\
June 3 & - & - & - & + & - & - & ++ & + & ++ \\
11 & - & - & - & ++ & + & + & no observation \\
20 & ++ & + & + & ++ & + & + & no observation \\
26 & ++ & + & ++ & ++ & + & - & + & - & - \\
July 29 & - & - & - & + & + & - & + & - & - \\
Aug. 28 & - & - & - & + & - & - & + & - & - \\
\hline
\end{tabular}

A: adults; : mounting pairs; E: egg masses. ++ : abundant; + : present; - : not found.

Table 2. Occurrence of mounting pairs and egg masses in areas $1 \mathrm{~m}$ width $\times 100 \mathrm{~m}$ along Lines 1 and 2 in 1976. For substrata, s: sand, r: rock, s-p: sand-pebble, m: mud. Other abbreviations are the same as in Table 1.

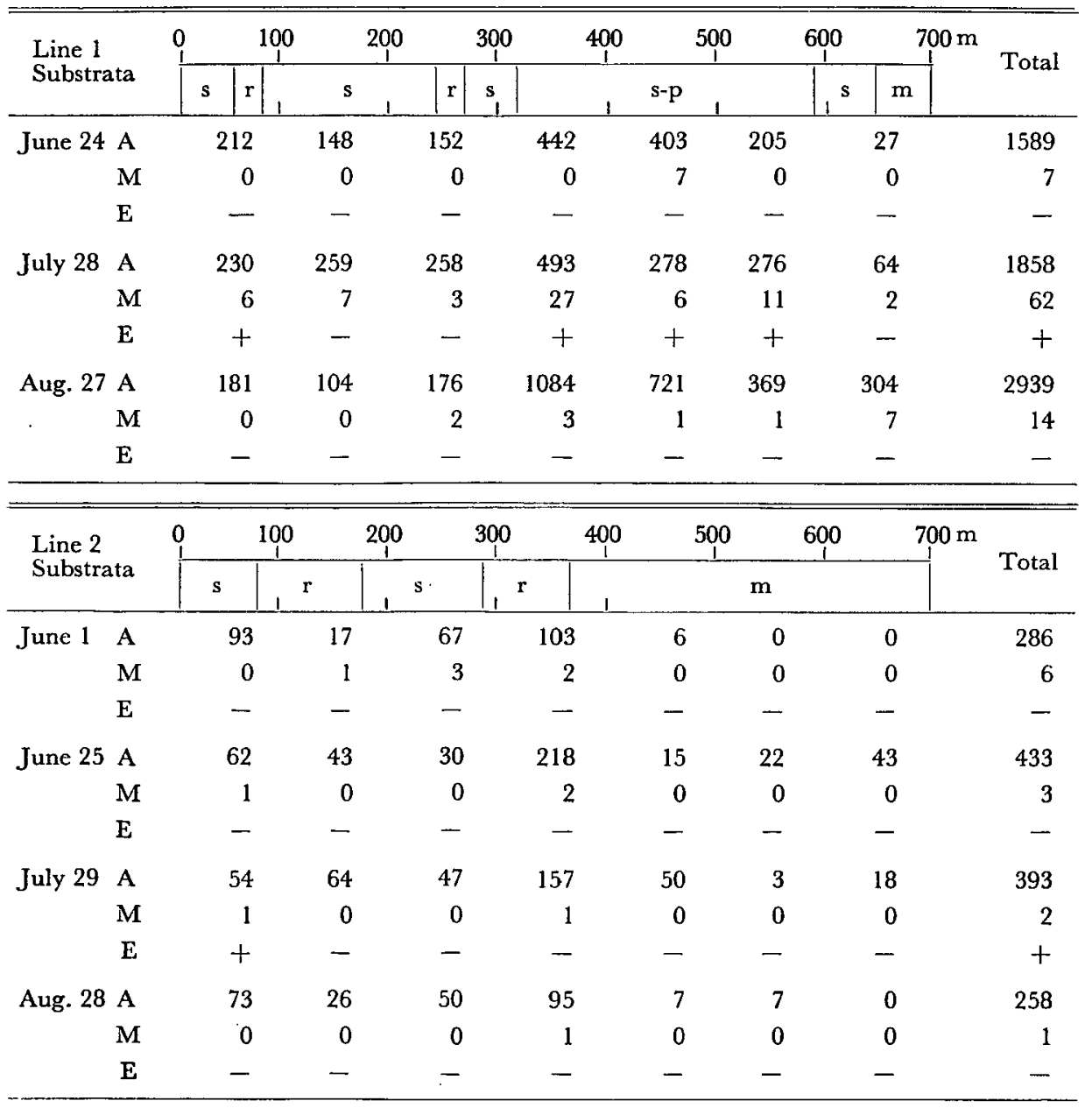


egg masses at Sts. A, B and C (Figs. 1 and 7) and Lines 1 and 2 (Fig. 1) is shown in Tables 1 and 2 respectively.

Many mounting adults and egg masses were first found at St. C in early June. Then, many adults began to aggregate at St. B. In late June, numerous adults appeared on the shore slope St. A, and many egg masses were found there. In early July, many adults were stranded and most of egg masses on the shore slope were swept away by the heavy swell caused by a typhoon. In late July, only a few adults were found at Sts. A and B, and spawning was rarely observed there. At that time, however, egg masses and mounting adults were commonly found in the areas 300 to $600 \mathrm{~m}$ offshore along Line 1. In late August, copulating animals were found only in the offshore areas, and no egg masses were found anywhere.

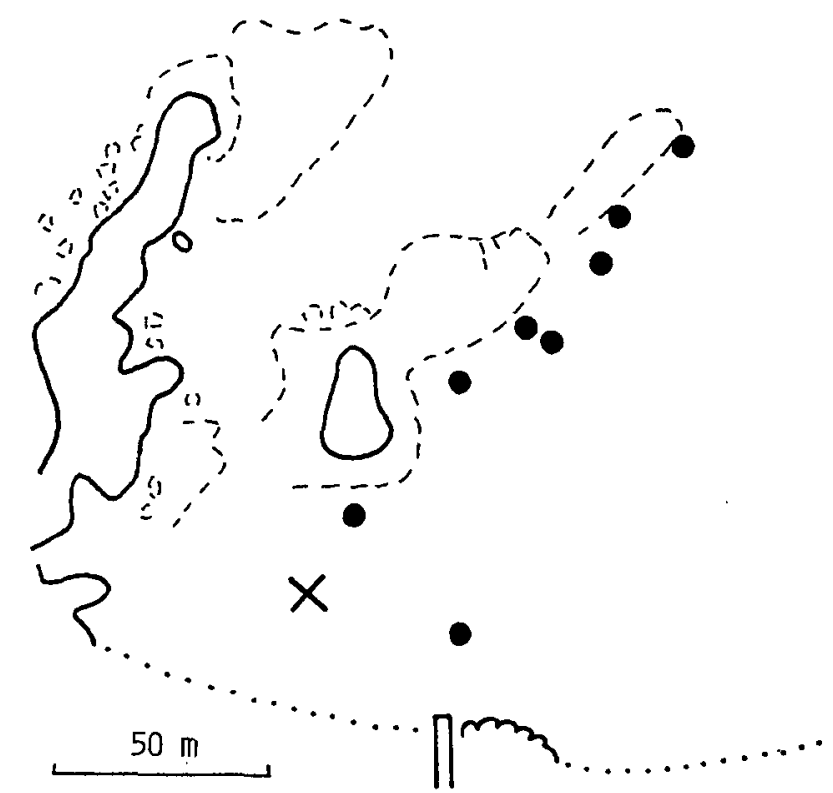

Fig. 8. Recaptured positions of the tagged conchs in September 1976. Each solid circle represents the position of each conch.

Numerous adults appeared near the shoreline (St. A) in late June, where no adults were found in other seasons. Some of the tagged adults were observed to migrate offshore from the shallow spawning site after the end of the spawning season (Fig. 8). Although almost the whole shoreline around the laboratory shown in Fig. 1 was inspected in late June, adults were found only at Sts. A and D, where the substrate was fine pebble and sand and they spawned, but no adults were found in other parts of the shoreline, which were covered with sand or rock. Sand-pebble bottoms were prefered for spawning sites also in the deeper areas (Table 2).

Observations in 1977: Copulation was seen from May 30 to July 16, and egg masses were found from June 8 to July 16. As in 1976, adults aggregated to copulate and spawn in the zone transitional from rocky reef to sand floor in the vicinity 
of St. G and on the sand flat to the northeast of Line 3. However, no aggregations of adults were observed in the shallower areas including Sts. A, B and D. On July 14, all the shoreline around Shirahama (Fig. 1) were surveyed, but neither egg masses nor adults were found. Mounting animals and egg masses were found less abundantly also in the deeper waters in 1977 than in 1976.

Seasonal change of gonad index: The change of the gonad index in the period from June 1976 to June 1977 is shown for the shallow and deep stations (Fig. 9). The gonad index was highest at the end of June 1976, then decreased into the lowest level at the end of August, and slightly increased from late April to early June 1977. The maturation of gonad seems to be partly affected by the water temperature, because (1) the gonad index increased with the increase of the temperature in spring (Fig. 9), and (2) as mentioned in the previous section, the lower spawning activity was observed in 1977, in which year the water temperature during winter and spring was lower than in 1976 (Fig. 9).

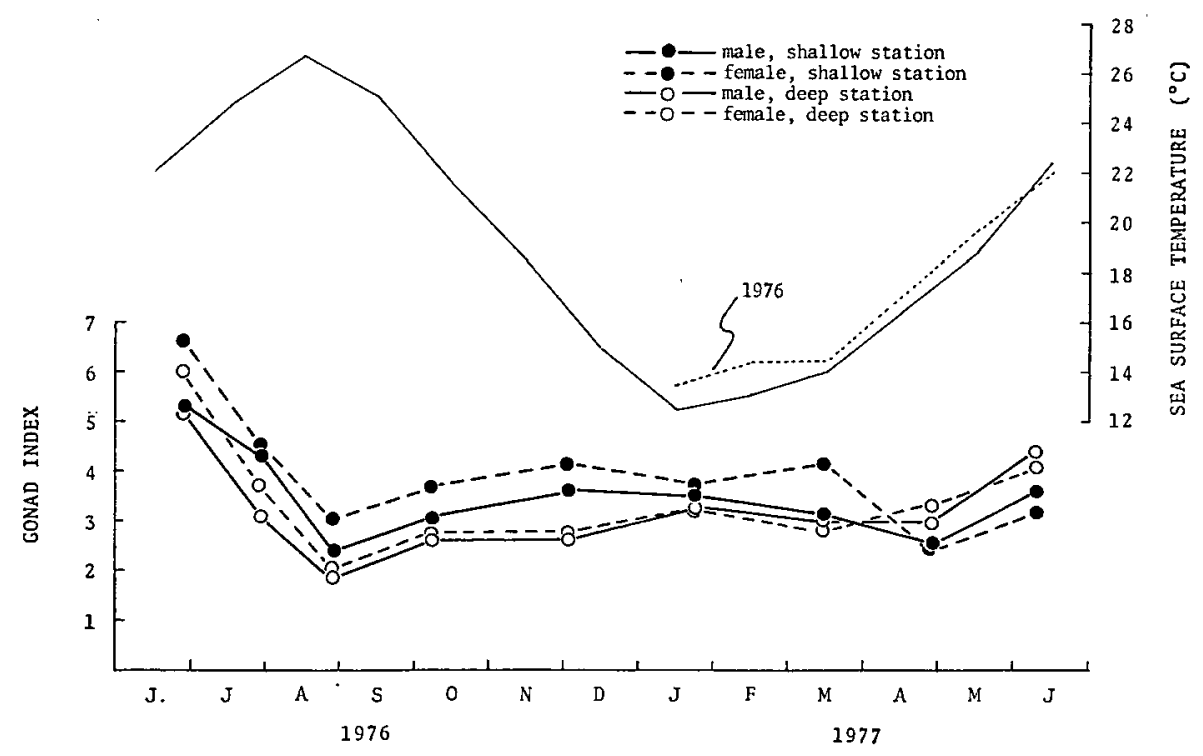

Fig. 9. Seasonal change of the gonad index, (gonad weight/body weight) $\times 100$, in $S$. luhuanus. Each circle shows the mean of about 20 individuals. Monthly averages of the water temperatures measured at 09:00 everyday at the north pier of the laboratory are also shown.

\section{Discussion}

The sexual dimorphism, mating and spawning behavior, and structure of the egg mass in Strombus luhuanus observed in the present study were generally similar to those of other congeners already reported.

It is well known to fishermen of Shirahama that many adults of $S$. luhuanus come into shallow water during the summer months. The present study revealed that they copulated and spawned there. Similar "onshore spawning migration" is 
known in S. luhuanus at Ryukyu Islands (Nishihira, pers. comm.) and in S. costatus, $S$. raninus and $S$. gigas in the Bahamas (Robertson, 1959). Abbott (1960) regarded it as a common habit of the genus Strombus. However, these conchs also spawn in much deeper waters (Robertson, 1959; Randall, 1964; D'Asaro, 1965; Berg, 1975; Brownell, 1977) as well as $S$. luhuanus in the present study.

In any depth $S$. luhuanus preferred to copulate and spawn at the sand-pebble bottom. Randall (1964) has suggested from the viewpoint of predation risk on eggs in $S$. gigas that (1) the conch leave seagrass beds for sand flats to spawn, probably because more predators on the egg masses are present in the former site, and (2) sand grains, which are usually adhered to the egg tube of Strombus species, are necessary for spawning as they serve both to provide camouflage for the egg mass and physically discourage predation (also see Robertson, 1959; D'Asaro, 1965). The latter suggestion may be applicable also to $S$. luhuanus, but it preferred the sandpebble bottom rather than bare sand one for spawning probably because the latter substrate is less stable than the former when the sea is rough.

From spring to summer, the population of $S$. luhuanus in the study area enlarged its distribution not only onshore but also offshore (Wada et al., 1983). The areas extended offshore were sand or mud flats (see Table 2), and few spawning occurred there. On the other hand, in the areas extended onshore the remarkable concentration of copulation and spawning was observed at the sand-pebble bottoms near the shoreline or reef margin. The concentration might be only a result of the process that as the shoreline or rocky reef constitute a barrier to further movement of the conchs, they consequently aggregate there and increase chances to find mates. From alternative viewpoints, however, these shallow spawning sites differ from deep ones in environmental factors such as the water temperature, current condition, abundance of predators, etc., which may affect upon the reproductive success in development and survival of eggs, larval dispersal and so on. However, no quantitative data are available at present. Comparative studies at different localities which have different topography and substrate are needed to clarify the relationship between the onshore migration and spawning in Strombus species.

\section{Acknowledgements}

The Seto Marine Biological Laboratory provided the facilities for the field and laboratory studies. We are indebted to the members of the staff of the laboratory. We are also grateful to Drs. E. Harada, M. Nishihira and M. Yamaguchi for critical commentary on earlier drafts of the manuscript.

\section{References}

Abbott, R.T. 1960. The genus Strombus in the Indo-Pacific. Indo-Pacific Mollusca, 1(2): $33-146$. Berg. C.J. 1975. Behavior and ecology of conch (superfamily Strombacea) on a deep subtidal algal plain. Bull. Mar. Sci., 25(3): 307-317.

Brownell, W.N. 1977. Reproduction, laboratory culture, and growth of Strombus gigas, $S$. costatus and S. pugilus in Los Roques, Venezuela. Bull. Mar. Sci., 27 (4): 668-680. 
D'Asaro, C.N. 1965. Organogenesis, development, and metamorphosis in the queen conch, Strombus gigas, with notes on breeding habits. Bull. Mar. Sci., 15(2): 359-416.

D'Asaro, C.N. 1970. Egg capsules of prosobranch mollusks from south Florida and the Bahamas and notes on spawning in the laboratory. Bull. Mar. Sci., 20(2): 414-440.

Ostergaard, J.M. 1950. Spawning and development of some Hawaiian marine gastropods. Pac. Sci., $4(2): 75-115$.

Randall, J.E. 1964. Contributions to the biology of the queen conch, Strombus gigas. Bull. Mar. Sci., 14(2): 246-295.

Risbec, J. 1936. Biologie et ponte de mollusques gastéropodes Néo-Calédoniens. Bull. Soc. Zool. France, $60: 387-417$.

Robertson, R. 1959. Observations on the spawn and veligers of conchs (Strombus) in the Bahamas. Proc. malac. Soc. London, 33(4): 164-171.

Wada, K., R. Fukao, T. Kuwamura, M. Nishida \& Y. Yanagisawa. 1983. Distribution and growth of the gastropod Strombus luhuanus at Shirahama, Japan. Publ. Seto Mar. Biol. Lab., 28(5/6): 417-432. 